\title{
UNAMUNO, EUROPA Y UN TRÁGICO SENTIR: ESTUDIO DE UN TEXTO OLVIDADO DE UNAMUNO
}

\author{
VICTORIA ALZINA LOZANO \\ Universidad Rey Juan Carlos
}

\section{Resumen}

Algunos de los retos que presenta el estudio de la obra de Unamuno es la prolijidad de esta y la enorme variedad de temas que reúne. Además, en cuanto a la parte ensayística, en su publicación la tendencia ha sido a la diseminación en diversas revistas, tanto del ámbito nacional como de fuera de nuestras fronteras. Esto ha propiciado que algunos textos queden olvidados durante décadas, fuera de las Obras completas, y, por último, no tenidos en cuenta en los distintos estudios en torno a la obra unamuniana. En este trabajo rescatamos un texto olvidado, "Más sobre la europeización», y lo estudiamos junto a su precedente, «Sobre la europeización», analizando los puntos comunes a Del sentimiento trágico de la vida. Planteamos, con el estudio textual, la necesidad de compleción de las Obras completas de Unamuno para garantizar un acercamiento más preciso a su obra, no solo desde un enfoque genético, sino también comparativo.

Palabras clave: Unamuno, europeización, sentimiento trágico, obras completas, ensayos.

\section{UNAMUNO, EUROPE, AND A TRAGIC SENSE: STUDY OF A FORGOTTEN TEXT OF UNAMUNO}

\begin{abstract}
Some of the challenges that the study of Unamuno's work presents is its prolixity and the enormous variety of themes that it brings together. Besides, as for the essay part, in its publication the tendency has been to disseminate it in different journals, both national and international. This has led to some texts being forgotten for decades, outside of the Complete Works, and, finally, not taken into account in the different studies on Unamuno's work. In this paper, we rescue a forgotten text, «Más sobre la europeización», and we study it along with its precedent, «Sobre la europeización», analyzing the common
\end{abstract}


points with Del sentimiento trágico de la vida. With this textual study, we present the need to complete Unamuno's Complete Works to guarantee a more precise approach to his work, not only from a genetic perspective, but also from a comparative one.

Keywords: Unamuno, europeanisation, tragic sense, complete works, essays.

\section{INTRODUCCIÓN}

El estudio de la obra unamuniana plantea diversos retos, y uno de los más evidentes es lo prolija y compleja que es esta producción escrita. Sus textos -nosotros nos centraremos en su ensayística- se publican durante décadas en diversas revistas, tanto nacionales como externas a nuestras fronteras; se dan traducciones, continuaciones y reediciones de los mismos. Se presenta, por ello, la articulística de Unamuno como un intrincado conjunto de textos, con una reconocible continuidad con su pensamiento e ideario, pero de difícil estudio relacional por haber quedado desperdigada y, en consecuencia, en muchos casos, olvidada.

El ejercicio de buscar, ordenar y completar la parte ensayística de la creación unamuniana no es nuevo. Debemos especiales menciones a García Blanco, precursor y editor de las primeras Obras Completas de don Miguel (Unamuno, 1958) o a Manuel Urrutia (Urrutia, 1997) al frente de trabajos más actuales cuyos esfuerzos se centran en recuperar artículos que habían caído en el olvido. El propio Unamuno, entre 1916 y 1918, se propone coleccionar ${ }^{1}$ sus artículos publicados en revistas españolas entre 1894 y 1911 -en siete volúmenes a cargo de Publicaciones de la Residencia de Estudiantes-, sus Ensayos (Unamuno, 1916-1918).

Si ponemos el enfoque en esta autoedición del bilbaíno, podemos apuntar que en estos volúmenes se encuentran recogidos todos los artículos que Unamuno publicó en La España Moderna, a excepción de tres: «Más sobre la europeización» e «Inteligencia y bondad» (Unamuno, 2011); y «El sepulcro de Don Quijote», que hará de prólogo a la segunda edición de Vida de Don Quijote y Sancho, publicada en 1905 (Unamuno, 1988), además de Del sentimiento trágico de la vida, que se publicaría

${ }^{1}$ Así denomina a su propio ejercicio de recopilación de sus artículos en la «Advertencia preliminar» de sus Ensayos y que firma en Salamanca en febrero de 1916 (Unamuno, 1916: 12). 
como un libro independiente en 1912 (Unamuno, 2005b). En este punto, la comparativa de los índices de La España Moderna y de los Ensayos nos ha desvelado vacíos relevantes: son realmente dos de estos artículos los que han quedado marginados del resto de su obra recopilada y, más tarde, ninguno de ellos volverá a aparecer en las Obras Completas.

Nos centraremos en este trabajo en estudiar la problemática de este vacío, en la necesidad de actualización y revisión de la obra ensayística de Unamuno a partir del estudio de uno de sus artículos capitales, «Sobre la europeización (arbitrariedades)»(Unamuno, 1906), que identificaremos a veces con la abreviatura "Sle», y su olvidada continuación, "Más sobre la europeización» (Unamuno, 1907), que abreviamos en «Msle», publicados en diciembre de 1906 y marzo de 1907, respectivamente.

\section{LA SUERTE EDITORIAL DE LOS TEXTOS}

Ya hemos advertido sobre la pésima, o nula, suerte editorial que ha sufrido "Msle», que queda olvidado tras su publicación en 1907, pero, cabría reflexionar sobre el porqué de esto. ¿Por qué Unamuno no recoge «Msle» en sus Ensayos? Analizando los índices de los diversos volúmenes de sus Ensayos, así como los índices de La España Moderna, vemos que Unamuno optó por recopilar sus artículos por orden cronológico ${ }^{2}$ e intercalar los insertos en La España Moderna con aquellos que aparecen en otras publicaciones periódicas. Es este orden cronológico el que nos permite advertir con facilidad que son los dos últimos ensayos ${ }^{3}$ que publica en La España Moderna -previos a Del sentimiento trágico de la vida- los que quedan fuera de Ensayos, y que el motivo de su exclusión no es, a priori, un descarte intencional de Unamuno.

Una posible justificación para la exclusión de «Msle» -y los otros dos artículos- en los Ensayos es que, quizá, estaba previsto un octavo volumen que no llegó a publicarse, o que por una cuestión de espacio no tenían cabida en esta edición, y debido al orden cronológico que Unamuno

${ }^{2}$ A excepción del segundo volumen, cuyos ensayos son previos a los del primero, decisión que Unamuno toma «a fin de no romper la unidad de los ensayos que forman "En torno al casticismo"»; esta es, al menos, la justificación que da Unamuno (1916-1918: I: 12).

${ }^{3}$ Obviamos «Parnaso español: Aldebarán», presente en los índices de La España Moderna, por tratarse de un poema. 
empleó para la elaboración de esta colección, estos últimos textos quedaron fuera. Esta ausencia no es solo destacable por el vacío que ha dejado en las Obras Completas, sino porque las ha condicionado directamente y evidencia la metodología de elaboración de este tipo de ediciones que, en la parte ensayística, se han conformado a partir de los Ensayos y de los libros publicados en vida de Unamuno; quizá el agradecimiento mayor se lo debamos a García Blanco, que hizo un enorme ejercicio de recopilación de textos, aunque, como vemos, siga teniendo algunos vacíos que llenar. Es por esto que podemos ver cómo «Sle», que sí aparece en el séptimo volumen de Ensayos, es recogido en las ediciones más destacadas de las Obras Completas de Unamuno; mientras que «Msle» quedará fuera de estas recopilaciones $\mathrm{y}$, por consiguiente, postergado.

Dentro de los estudios de la obra y el pensamiento de Unamuno, la europeización ha suscitado, sin duda, un considerable interés. Son muchos los trabajos disponibles en los que podemos encontrar alusiones a «Sle» y citas extraídas de este texto para abordar cuestiones como la problemática de Europa a principios del siglo XX (García, 1988: 19-38), el propio pensamiento político de Unamuno (Urrutia, 1997: 112) o, incluso, encuadrar las etapas filosóficas del bilbaíno (Robles, 2008: 271). Pero, más allá de usar la pieza como fuente para el estudio de diversas cuestiones o de otros escritos unamunianos (sin otorgarle una excesiva importancia), no se ha llevado a cabo ningún análisis íntegro sobre dicho texto. Esta es sin duda una tendencia en los estudios que circundan la ensayística unamuniana. Podríamos afirmar que este y los otros artículos que abordan el problema de Europa no han sido tomados como punto focal de ningún estudio, sino que se ha recurrido a «Sle»-no encontramos citado «Msle»- para abordar algunas de las temáticas mencionadas anteriormente.

Sabemos que entre los contemporáneos de don Miguel, «Sle» generó cierto interés. En la prensa hemos podido localizar dos artículos que fueron una respuesta explícita a dicho texto: el de Miguel S. Oliver, titulado «El culto a la tristeza» y publicado en $A B C$ en diciembre de 1906 (Oliver, 1906), y al que el propio Unamuno aludirá en «Msle»; y el de Baltasar Champsaur «Hacia la cultura europea», publicado en la Revista Contemporánea entre abril y mayo de 1907 (Champsaur, 1907). Asimismo, podemos encontrar ciertas alusiones, como la de Luis Araquistain: «Unamuno nos ha dicho más de una vez que él es un africano, o cuando más 
un español, pero de ningún modo un europeo» (Araquistain, 1914: 100), posiblemente, por las referencias a la sabiduría africana como propia de los españoles o defender el origen berberisco de nuestra cultura, así como el rechazo a la cultura europea moderna; todas ellas son cuestiones en las que se reafirma Unamuno a lo largo de «Sle».

Además, este es sin duda uno de los textos sobre la problemática europea que provocan la escisión entre Unamuno y Ortega y Gasset. El conocido texto de la conferencia que Ortega pronuncia en Bilbao en 1910, publicado bajo el título de «La pedagogía social como programa político» (Ortega y Gasset, 1946: 494-513) es indiscutiblemente una respuesta directa al texto de don Miguel; apreciable sobre todo en la "Conclusión», con una interpelación en la que son rebatidos algunos de los puntos clave de «Sle». Si bien la famosa polémica encontró su punto de máxima tensión dos años después de la aparición de nuestros textos y uno antes de la conferencia de Ortega, en el artículo publicado por este en El Imparcial en septiembre de 1909, con el título de «Unamuno y Europa, fábula» (Ortega y Gasset, 1909: 3), acusaba al rector de Salamanca de «energúmeno español» por sus posturas anti-europeizantes, palabras que hieren profundamente al bilbaíno, como apunta Orringer (2005: 65-66), quien considera que esta situación es la que motiva a Unamuno a reelaborar definitivamente su Tratado (Ortega y Gasset, 1909: 3). Un aspecto que hay que destacar en cuanto a la repercusión inmediata del texto es que algunas de estas respuestas motivaron la propia réplica de Unamuno, que se verá impulsado a responder a las críticas y, así, a la composición de «Msle», como veremos ahora.

\section{UN ÚNICO TEXTO}

No es extraño encontrar entre la obra ensayística de Unamuno varios artículos con títulos similares o que sean evidentes ampliaciones o anotaciones de un primer ensayo. Sin embargo, Unamuno no siempre fue tan explícito con esto. Creemos que en el caso de «Sle» y «Msle» es evidente que son las dos partes de un mismo ensayo compuesto con una diferencia de tiempo muy pequeña y cuya segunda parte, «Msle», nació a propósito de esclarecer cuestiones presentes en «Sle» y como respuesta a las ya comentadas reacciones de otros autores. Parece claro que Unamuno lo 
consideraba una continuación a lo publicado en diciembre de 1906, cuando escribe «[...] quiero empezar esta continuación y comento al ensayo que, bajo el título de Sobre la europeización, publiqué en el número de Diciembre de 1906 de esta misma Revista» (Unamuno, 1907: 5); y además sabemos que lo utilizó parcialmente para responder a ciertas apreciaciones que se hicieron sobre la primera parte: «Con esto salgo al paso de ciertos discretos y muy juiciosos reparos que Miguel S. Oliver hizo a mi anterior ensayo, en su artículo, "El culto a la tristeza", muy razonado y muy justo, que publicó en el $A B C$ del 24 de Diciembre de 1906» (Unamuno, 1907: 5).

Otra observación que nos anima a afirmar que es un único texto bimembre es lo encontrado en el Índice de artículos publicados de La España Moderna, donde podemos ver que se recogen los dos que nos ocupan como un único artículo publicado en dos fechas distintas bajo el título de «Sobre la europeizacíon». En la entrada 4744 (y 1706) de este Índice se especifica: "Sobre la europeización"; artículo de Miguel de Unamuno. - T. 216; págs. 64-83. Diciembre, 1906, y T. 219; págs. 5-23. Marzo, 1907». Ni siquiera se recoge el «Más» que da pie a que sea un añadido al texto primero (Villafranca, 1922).

Este dato es el apunte final que soporta la idea de que los ensayos que nos atañen pueden considerarse como un único texto en dos partes, pues ese es el tratamiento que se le da en la revista. No obstante, la negativa la encontramos en que «Msle» no aparezca en los Ensayos. Podríamos entender que no le correspondiera ir inmediatamente después de «Sle» en dicha colección -por el orden cronológico empleado-, pero definitivamente sí en un hipotético octavo volumen. Nada apuntaría aparentemente a que don Miguel rechazase dicho texto, por lo que sería más bien una desafortunada cuestión editorial.

Además, y por último, podemos hablar de un único texto por la concordancia entre los títulos y porque ambas partes siguen un mismo hilo hasta llegar, de nuevo, a la misma conclusión, la españolización de Europa como acercamiento a la cultura, y el progreso, europeos:

Si hay español que quiera rendirse, ríndase; pero yo solo bajaré mi corazón, para ponerlo a su amparo, ante el corazón de quien, con las armas de la civilización europea en la mano, y reventando en fe, diga: Europa empieza en los Pirineos; ja conquistarla! (Unamuno, 1907: 23). 
Sean, pues, aquí mis últimas palabras, mientras me preparo a pensar cómo pueda españolizarse a Europa, que nada digno de ser probado puede ni probarse ni desprobarse (Unamuno, 1906: 83).

\section{PRESENCIA EN DEL SENTIMIENTO TRÁGICO DE LA VIDA}

Pese a la complejidad y continua evolución del pensamiento unamuniano, hay una serie de ideas constantes que lo vertebran: la muerte, el conflicto entre razón y pasión, la fe, la regeneración de España... son solo algunas de las cuestiones que conforman el denso pensamiento de Unamuno, que junto a sus referentes -Santa Teresa, San Juan, San Agustín, Spinoza, entre otros tantos- completan el entramado de su ideario. "En rigor desde que empecé a escribir he venido desarrollando unos pocos y mismos pensamientos cardinales», concluye Unamuno (1916-1918: I: 12) en uno de sus ensayos.

Estas recurrencias son pensamientos cardinales que estructuran y orientan la obra de Unamuno. Esto nos lleva a pensar que un alto número de coincidencias entre textos no puede interpretarse -en este caso- como una relación genética entre dos o más piezas; pero sí permite confirmar una relación muy estrecha entre algunas de ellas. El estudio de Orringer del Tratado del amor de Dios como principal origen de Del sentimiento trágico de la vida tiene un oportuno fundamento, pues son bastantes las páginas exactas que pasan de una obra a otra y se aprecia claramente cómo la segunda es una reelaboración de la primera. Además, Unamuno explicitó la realidad de que ambas obras eran una sola. Sin embargo, el resto de páginas es una serie de nuevas aportaciones de Unamuno, a partir de notas coleccionadas durante años ${ }^{4}$; y pese a que podríamos interpretar que estas notas son la génesis de Del sentimiento, más bien lo son de toda la obra ensayística de don Miguel. Posiblemente «Sle», «Msle» y Del sentimiento trágico estén construidos sobre los mismos apuntes que Unamuno habría tomado, y por ello, encontramos citas casi exactas,

${ }^{4}$ En el capítulo final de Del sentimiento trágico de la vida, Unamuno dirá que sus ensayos: «Han ido saliendo de mis manos a la imprenta en una casi improvisación sobre las notas recogidas durante años, sin haber tenido presentes al escribir cada ensayo los que precedieron. Y así irán llenos de contradicciones íntimas -al menos aparentes-, como la vida y como yo mismo» (Unamuno, 2005b: 472). 
ideas repetidas, reescrituras de una misma noción, etc., que no se traducen en que «Sle» y «Msle» sean parcial génesis de Del sentimiento trágico de la vida, pero sí una prueba de que el trágico sentimiento de Unamuno empapaba toda su obra y no solo su Tratado del amor de Dios. Vida de Don Quijote y Sancho, Tratado del amor de Dios, «Sle» y «Msle» se componen en una franja temporal de apenas tres años, e incluso llegan a solaparse en su composición, y es en este momento en el que el escritor comienza a trabajar la forma de plasmar ese trágico sentir; y aquí es donde nos separamos de las apreciaciones de Orringer (2005: 21), que afirma que el título, junto a otras cuestiones, "tuvieron que ser felices ocurrencias de última hora». Sin embargo, la idea de sentimiento trágico (sentimiento de la vida) aparece en «Msle»:

Hubo un momento en la Historia en que España, dentro de las formas tradicionales del pensamiento de entonces, impuso en cierta medida su concepción y, más que concepción, sentimiento, sentimiento de la vida. ¿Qué hizo Íñigo de Loyola? (Unamuno, 1907: 18).

Ello es una lucha trágica y a brazo partido con el misterio; ello es un combate de noche y de día, con la cabeza ardiendo en Dios, según la vigorosa expresión de Oliveira Martins (Unamuno, 1907: 16).

Y en «Intelectualidad y espiritualidad», de 1904:

Yo -piensa nuestro hombre- quiero hacer el mundo mío, hacerle yo, y el mundo trata de hacerme suyo, de hacerme él; yo lucho por personalizarlo, y lucha él por despersonalizarme. Y en este trágico combate, porque sí, el tal combate es trágico, tengo que valerme de mi enemigo para domeñarle, y mi enemigo tiene que valerse de mí para domeñarme (Unamuno, 1916-1918: IV: 202).

Por ello, podríamos afirmar que no son «ocurrencias» sino ideas que acompañan a Unamuno y que va cultivando hasta otorgarles un papel protagonista en Del sentimiento trágico. Pocas cosas pueden ser «felices ocurrencias», a nuestro parecer, en Del sentimiento trágico de la vida, pues son ideas traídas de ese continuo pensamiento de Unamuno y que ya quedan plasmadas en textos previos. Podemos hacer una comparativa de algunos fragmentos e ideas presentes tanto en Del sentimiento (y Tratado del amor de Dios) como en los dos artículos que nos ocupan. 
Además, estos también presentan paralelismos con obras como Vida de Don Quijote y Sancho o En torno al casticismo.

En «Sle», Unamuno cita un poema de Tennyson, al que añade su propia traducción al español, y que vuelve a recoger en Del sentimiento trágico. Copiamos aquí los dos fragmentos:

For nothing worthy proving can be proven

Nor yet disproven: wherefore thou be wise,

Cleave ever to the sunnier side of doubt,

And cling to Faith beyond the forms of Faith!

Fue Lord Tennyson, en El antiguo sabio (The Ancient Sage), el que dijo eso que, puesto en castellano -lengua en que debió haberse dicho primero tal cosa- dice: «Nada digno de ser probado puede aprobarse ni desaprobarse, y, por lo tanto, sé prudente y, ateniéndote siempre a la parte más soleada de la duda, agárrate a la fe más allá de las formas de la fe!» [...] que nada digno de ser probado puede ni probarse ni desaprobarse (Unamuno, 1906: 82-83).

[...] porque nada digno de probarse puede ser probado ni desprobado, por lo cual sé prudente, agárrate siempre a la parte más soleada de la duda y trepa la Fe allende las formas de la Fe!» Sí, acaso como dice el sabio, nada digno de probarse puede ser probado ni desprobado (Unamuno, 2005b: 138).

También en el primer artículo de 1906 encontramos el rechazo a las corrientes renacentistas que entraron en España para acabar con el alma medieval. Y si bien allí se admitía que estas corrientes afectaron a esta alma medieval de los españoles -cosa que ya había afirmado en En torno al casticismo- en Del sentimiento los españoles no se dejaron tocar el alma por estos cambios:

Y entró en España la poderosa corriente del Renacimiento, y nos fué borrando el alma medieval. Y el Renacimiento era en el fondo todo eso: ciencia, en forma sobre todo de Humanidades, y vida. Y se pensó menos en la muerte, y se fué disipando la sabiduría mística (Unamuno, 1906: 68).

En España penetró tanto como donde más el soplo del humanismo, el alma del Renacimiento, que siempre tuvo altar aquí. Desde dentro y desde 
fuera nos invadió el humanismo eterno y cosmopolita, y templó la mística castellana castiza (Unamuno, 2005a: 230).

Siéntome con un alma medieval, y se me antoja que es medieval el alma de mi patria; que ha atravesado esta, a la fuerza, por el Renacimiento, la Reforma y la Revolución, aprendiendo, sí, de ellas, pero sin dejarse tocar el alma, conservando la herencia espiritual de aquellos tiempos que llaman caliginosos (Unamuno, 2005b: 504-505).

La dicotomía sabiduría-ciencia aparece de forma muy similar, introduciendo en ambas obras la relación de las traducciones del término 'sabiduría'; no obstante, en Del sentimiento incluye también las traducciones para 'ciencia', que omite en "Sle», donde incide en la contraposición entre los términos y su preferencia por la sabiduría. En el artículo en La España Moderna escribió:

Ni necesito inventar una palabra para decir lo que contrapongo a la ciencia, porque esa palabra existe y es sabiduría: la ságesse de los franceses, la wisdom de los ingleses, la Weisheit o Klugheit alemana. Pero ¿es que se opone a la ciencia?, se medirá. Y yo, siguiendo mi método de arbitrariedad, guiado por mi pasión de ánimo, por mis íntimas repugnancias y mis íntimas atracciones, respondo: sí, se oponen, la ciencia quita sabiduría a los hombres y les suele convertir en unos fantasmas cargados de conocimientos (Unamuno, 1906: 66).

Y en su ensayo de 1912:

En todos estos pasajes donde he traducido ciencia, dice lord Byron knowledge, conocimiento; el francés science y el alemán Wissenschaft al que muchos enfrentan la wisdom-sagesse francesa y Weisheit alemanala sabiduría (Unamuno, 2005b: 237).

Encontramos también una reescritura del rechazo a la falsa idea de felicidad, que es bastante más cercana entre «Sle» y Tratado del amor de Dios, que en Del sentimiento. Así, en el primer artículo, dice: «Fue un error como el de aquellos que creen ser felices sin serlo. (Claro está que rechazo, arbitrariamente por supuesto, la idea de que el ser feliz consista en creer serlo)»(Unamuno, 1906: 66); mientras que en el Tratado se pregunta: "Quién dice: son felices!? No, no son felices. A lo sumo creen serlo, pero es que no hay más terrible infelicidad que la de aquel que se cree feliz, porque la suya ni infelicidad es siquiera, sino que es pura nada, 
inconsciencia» (Unamuno, 2005b: 602); que repite en su otro ensayo: "¿Sois felices?, pregunta Caín en el poema byroniano a Lucifer, príncipe de los intelectuales, y este le responde: "Somos poderosos"; y Caín replica: “¿Sois felices?” Y entonces el gran intelectual le dice: “No; ¿lo eres tú?”»(Unamuno, 2005b: 236).

Por último, repite en «Sle» y Tratado del amor de Dios la imagen de la regeneración del mundo según el imaginario cristiano, cuya conexión explícita es esa oración De profundis:

Y, en cambio, en medio de muchedumbres acongojadas que clamen al cielo pidiendo clemencia, que entonen un de profundis o un miserere, me habré de encontrar siempre como entre hermanos, unido a ellos por el amor (Unamuno, 1906: 71).

¡Cuánto mejor si pudiéramos derribar todos los soberbios edificios que elevó la necedad humana, romper los mármoles, quemar las telas y pasarnos la vida elevando a Dios un continuo de profundis! [...] así se encenderían y consumirían, y la tierra toda un incendio de amor (Unamuno, 2005b: 601).

Estudiados estos paralelismos, que se escapan a la crítica, no por falta de agudeza, sino por ese artículo traspapelado que ha sido «Msle» durante décadas y la, a veces, falta de atención que ha recibido «Sle»; nos queda solo apuntar dos fragmentos que consideramos que estudiados juntos se complementan, y permiten acceder a una definición más completa del sentimiento trágico. En el segundo artículo de 1907 escribe:

Ello es un combate trágico. Sí, solemnemente trágico; os lo digo yo, que lo sé muy bien. [...] . El combate inacabable entre el corazón y la cabeza es la acción más divinamente trágica que ha podido ofrecernos el destino. En ella no hay ni vencimiento ni victoria, pero tampoco hay tregua ni descanso.

Y este combate que se prosigue sin término en el interior de cada hombre llegado a plenitud de conciencia propia, este mismo combate se riñe entre los pueblos y las edades en el vasto tablado del mundo. Consulte, pues, cada español, puesta la mano sobre su corazón, los latidos del corazón de la patria, y piense después qué camino hemos de tomar si no hemos de desaparecer como pueblo que tiene su lugar y su fin en el concierto de la cultura humana (Unamuno, 1907: 22). 


\section{Y en Del sentimiento trágico:}

En lo que de estas reflexiones sobre el sentimiento trágico resta [...] al final pienso recogerlo todo y sostener que esa desesperación religiosa que os decía, y que no es sino el sentimiento mismo trágico de la vida, es, más o menos velada, el fondo mismo de la conciencia de los individuos y de los pueblos cultos de hoy en día, es decir, de aquellos individuos y de aquellos pueblos que no padecen ni de estupidez intelectual ni de estupidez sentimental. [...] Si en lo que va a seguir os encontráis con apotegmas arbitrarios [...] no os llaméis a engaño. Vamos a entrar, si queréis acompañarme, en un campo de contradicciones entre el sentimiento y el raciocinio, y teniendo que servirnos del uno y del otro (Unamuno, 2005b: 263).

En estos fragmentos creemos que se encuentra la clave para entender los límites del sentimiento trágico, la interpretación que nosotros juzgamos más completa y que difiere de la interpretación de Orringer. El sentimiento trágico como definición general puede entenderse como la lucha entre fe y razón, pero sin duda va más allá del conflicto filosóficoreligioso. Posturas como la de Urrutia (1997: 130) son las que a nosotros nos parecen más acertadas:

Tanto la Vida de don Quijote y Sancho como, sobre todo, el STV caben interpretarse como una verdadera lucha contra «la ortodoxia inquisitorial científica moderna». Inquisición que, por otro lado, al igual que la histórica, no es algo meramente externo sino también y principalmente inmanente, de ahí el carácter trágico.

El sentimiento trágico como lucha entre razón y fe es también la lucha entre ciencia y sabiduría, lógica y pasión o vida y muerte, que vemos en los dos artículos que nos han ocupado en estas líneas. La europeización es la imposición de la lógica y la pasión es el ingrediente fundamental de la españolización de Europa. No obstante, en estas dicotomías no existe un claro concepto vencedor para Unamuno, sino que don Miguel abogó por un equilibrio entre ambas tendencias. Él quiso encontrar un punto medio e invitar a proceder bajo una postura crítica:

Pero es que mi obra -iba a decir mi misión- es quebrantar la fe de unos y de otros y de los terceros, la fe en la afirmación, la fe en la negación y la fe en la abstención, y esto por fe en la fe misma; es combatir a todos los que se resignan, sea al catolicismo, sea al racionalismo, sea al 
agnosticismo; es hacer que vivan todos inquietos y anhelantes (Unamuno, 2005b: 505).

Si la razón es la seña de lo europeo moderno, y la fe un elemento fundamental en la cultura española, el debate de la europeización es una lucha paralela al sentimiento trágico o, incluso, está integrada dentro de este. Si la integración fuese la opción correcta, entonces podríamos explicar la importancia que dio Unamuno a este asunto -pues es con el que cerró su Del sentimiento-, el cual no dejará de tratar desde que publicase los cinco ensayos en La España Moderna de En torno al casticismo en 1895. Además, no podemos olvidar que este debate en torno a Europa es, como ya comentábamos al comienzo de estas páginas, el que provocó la ruptura definitiva entre Unamuno y Ortega, y es este mismo conflicto entre ambos intelectuales el que motivará a Unamuno a incluirlo en las páginas que publica entre finales de 1911 y durante todo 1912.

Solo hemos encontrado un testimonio en que se considere a «Sle» como origen parcial de Del sentimiento trágico junto a otros ensayos de Unamuno, algunos inéditos en España o que no volvieron a publicarse tras su primera aparición:

Sin embargo, su obra, así como todas las obras filosóficas, tiene una génesis muy peculiar, y son precisamente estos escritos: De la desesperación religiosa moderna (1907), Inteligencia y bondad (1907) y Jesús o Cristo (1910) los que constituyen y desvelan la génesis de la obra unamuniana. Esto, claro, sin olvidar por ejemplo el ensayo de 1906 titulado «Sobre la europeización» donde ya es patente la crítica contra el racionalismo y los reclamos hacia la «razón hedieran» que ha convertido al hombre en un «ideal» gracias a su lógica inflexible y no en un hombre concreto de carne, cuya lógica sea la del corazón, o «cardíaca», como la llama Unamuno (Rincón, 2012: 171).

Y si bien estamos de acuerdo con las ideas que se extraen de «Sle» en este ensayo, no consideramos que estas obras sean tanto génesis de $\mathrm{Del}$ sentimiento como una innegable evidencia de que el trágico sentir de Unamuno engloba más que el explícito problema religioso del Tratado del amor de Dios. Prueba de esto es su recomposición y extensión que lo convertirá en la obra cúspide que es Del sentimiento trágico de la vida. 


\section{BIBLIOGRAFÍA CITADA}

ARAQUiStain, L. (1914): «Unamuno y el europeísmo». Hispania, 30, 1108-1110. ChAMPSAUR, B. (1907): «Hacia la cultura europea». Revista Contemporánea, Madrid, 15 de abril y 15 de mayo, tomo CXXXIV, cuaderno IV, 395-405 y V, 537-555.

García, J. M. (1988): «El lenguaje del hijo pródigo», Diálogos Hispánicos, 7, 1938.

OlIVER, M. S. (1906): «El culto a la tristeza». $A B C$, Madrid, 24 de diciembre, 3-4.

ORRINGER, N. (2005): «Introducción» (Unamuno, 2005b: 15-92).

ORTEGA Y GASSET, J. (1909): «Unamuno y Europa, fábula». El Imparcial, Madrid, 27 de septiembre, 3.

ORTEGA Y GASSET, J. (1946): «La pedagogía social como programa político». En: Obras Completas. Madrid: Revista de Occidente, 494-513.

Rincón, J. E. (2012): [Reseña] M. de Unamuno, De la desesperación religiosa moderna, edición y traducción de Sandro Barzoni. Madrid: Trotta, 2011. Open Insight, 3.4, 169-174.

Robles CARCEDo, L. (2008): «Edición del texto inédito de Unamuno: Notas de Filosofía, I». En Chagueda Toleado, A. (ed.): Miguel de Unamuno. Estudios sobre su obra. III. Salamanca: Universidad de Salamanca, 271.

UNAMUNO, M. de (1906): «Sobre la europeización (arbitrariedades)». La España Moderna, 216, diciembre, 64-83.

UnAmuno, M. de (1907): «Más sobre la europeización». La España Moderna, 219, marzo, págs. 5-23.

UnAmuno, M. de (1916-1918): Ensayos. I-VII. Madrid: Residencia de Estudiantes.

UnAmuno, M. de (1958): Obras completas. Ed. M. García Blanco. Madrid: Afrodisio Aguado.

Unamuno, M. de (1988): Vida de Don Quijote y Sancho. Ed. A. Navarro. Madrid: Cátedra.

UnAmuno, M. de (2005): En torno al casticismo. Ed. J.-C. Rabaté. Madrid: Cátedra.

Unamuno, M. de (2005): Del sentimiento trágico de la vida en los hombres y los pueblos y Tratado de amor de Dios. Ed. N. Orringer. Madrid: Tecnos.

UnAmuno, M. de (2011): De la desesperación religiosa moderna. Ed. y trad. S. Borzoni. Madrid: Trotta.

Urrutia, M. (1997): Evolución del pensamiento político de Unamuno. Bilbao: Universidad de Deusto. 
VILLAFRANCA, R. G. (1922): Índices de materias y autores de La España Moderna. Tomos $1^{\circ}$ a 264. Enero de 1869 a diciembre de 1910. Formados aplicando el sistema de clasificación bibliográfica decimal. Madrid: La España Moderna.

Victoria ALZINA LOZANO Universidad Rey Juan Carlos victoria.alzina@urjc.es https://orcid.org/0000-0002-1245-067X 
